\title{
A família Malpighiaceae em uma área de savana em Roraima, Brasil
}

\author{
Joana Menezes $^{1}$ e Andréia Silva Flores ${ }^{2,3}$
}

1. Faculdades Cathedral, Curso de Bacharelado e Licenciatura em Ciências Biológicas, Avenida Luis Canuto Chaves 293, Boa Vista, CEP 69307-053, Roraima.

2. Instituto de Amparo a Ciência, Tecnologia e Inovação de Roraima (IACTI-RR), Herbário do Museu Integrado de Roraima (MIRR), Av. Brigadeiro Eduardo Gomes 1128, CEP 69330-640, Boa Vista, RR, Brasil.

3. Autor para correspondência: andreiasflores@gmail.com

Recebido em: 10/09/2013 Aceito em: 05/11/2013.

\section{RESUMO}

\begin{abstract}
A família Malpighiaceae em uma área de savana em Roraima, Brasil. Malpighiaceae é uma das famílias mais diversas nas savanas de Roraima, sendo muito características neste tipo de vegetação. Este trabalho teve por objetivo realizar o estudo taxonômico de Malpighiaceae em uma área de savana em Boa Vista, Roraima. O tratamento taxonômico foi baseado na análise de exsicatas dos herbários de Roraima e em observações de campo. Foram encontrados três gêneros previamente citados para Roraima na literatura consultada. Byrsonima foi o gênero mais numeroso, apresentando quatro espécies, enquanto que Camarea e Tetrapterys foram registrados por apenas uma espécie cada. Tetrapterys styloptera é uma nova ocorrência para flora de Roraima. Este estudo também fornece chave de identificação, ilustrações, breves descrições e comentários para os táxons encontrados na área de estudo.
\end{abstract}

PALAVRAS-CHAVE: Taxonomia. Byrsonima. Escudo das Guianas. Amazônia.

\begin{abstract}
The family Malpighiaceae in a savana area of Roraima, Brazil. Malpighiaceae is one of the most diverse families in the savannas of Roraima state and very characteristic in this type of vegetation. This study carried out a taxonomic study of Malpighiaceae in a savanna area in Boa Vista City, Roraima State. The taxonomic treatment is based on the analysis of specimens from the two herbaria of Roraima and field observations. We found three genera previously cited in the literature for Roraima. Byrsonima was the most diverse genus, with four species, while Camarea and Tetrapterys were recorded by only one species each. Tetrapterys styloptera is a new record for the flora of Roraima. This study also provided identification key, illustrations, brief descriptions and comments on these taxa.
\end{abstract}

KEYWORDS: Taxonomy. Byrsonima. Guiana Shield. Amazon basin.

\section{INTRODUÇÃO}

A família Malpighiaceae apresenta distribuição geográfica pantropical, sendo mais diversa na América do Sul, compreendendo cerca de 77 gêneros e 1300 espécies, incluindo trepadeiras, árvores e arbustos (Davis \& Anderson 2010). Para o Brasil são citados 44 gêneros e 528 espécies de Malpighiaceae e para Roraima, 11 gêneros e 27 espécies (Mamede et al. 2013). A família é facilmente reconhecida pela presença de glândulas de óleo dispostos aos pares na base das sépalas de quase todas as espécies (Davis \& Anderson 2010). Dentre os gêneros que constituem essa família, Byrsonima é considerado um dos maiores com 125 espécies, agrupando espécies de grande importância medicinal, ornamental e produtoras de frutos comestíveis e cosméticos (Ribeiro et al. 1999; Anderson 2001).
As espécies de Malpighiaceae são ervas, arbustos, arvores ou lianas, possuem folhas geralmente opostas, simples, estípulas frequentemente presentes. As inflorescências podem ser cimosas ou racemosas com flores vistosas, geralmente bissexuadas, actinomorfas ou zigomorfas. As espécies apresentam também flores pentâmeras, pétalas geralmente unguiculadas, com 10 estames, gineceu tricarpelar, ovário súpero com estiletes distintos. Os frutos são, na maioria das vezes, esquizocárpicos, frequentemente alados, ocasionalmente bagas ou drupas (Anderson 2001).

A paisagem de savanas é formada por uma cobertura vegetal de cerca de $41.000 \mathrm{~km}^{2}$, ou seja, pouco mais de $19 \%$ da área do estado, que se distribuem entre os paralelos $2^{\circ}$ e $5^{\circ}$ de latitude norte e os meridianos $59^{\circ}$ e $62^{\circ}$ oeste. As savanas estão situadas em todo o sistema 
geomorfológico da formação Boa Vista e fazem parte do grande complexo compreendido entre Brasil Guiana e Venezuela (Miranda \& Absy 1997).

Embora Malpighiaceae não seja considerada uma das principais famílias representadas nas savanas de Roraima, muitas espécies são abundantes e características desta vegetação (Miranda \& Absy 1997). As informações sobre a ocorrência das espécies da família nas savanas do estado estão fragmentadas em poucos estudos florísticos. Rodrigues (1971) citou Camarea affinis St.-Hil. para os campos do Rio Branco, referindo-se às savanas próximas ao Rio Branco em Boa Vista. Além deste estudo, Miranda \& Absy (1997) citaram sete espécies da família na flora fanerogâmica das savanas de Roraima: Banisteriopsis muricata (Cav.) Cuatrec., Byrsonima coccolobifolia Kunth, B. crassifolia (L.) Kunth, $B$. schomburgkiana Benth., B. stipulacea A. Juss., B. variabilis A. Juss., B. verbascifolia (L.) DC. Segundo estes autores, estas espécies são encontradas em ambientes de mata e ambientes abertos, como savana parque, graminosa e arbórea.

Em Roraima, são poucos os estudos florísticos e taxonômicos, principalmente nas áreas de savanas (Flores \& Rodrigues 2010; Costa et al. 2012). Aliado a isto, não há nenhum estudo enfocando a taxonomia das espécies de Malpighiaceae no Estado. Portanto, este estudo visa apresentar o tratamento taxonômico da família Malpighiaceae nas diversas fitofisionomias em uma área de savana em Boa Vista.

\section{MATERIAL E MÉTODOS}

Área de estudo: $\mathrm{O}$ estudo foi realizado no Campus do Cauamé, pertencente ao Centro de Ciências Agrárias da Universidade Federal de Roraima (UFRR), localizado no município de Boa Vista, Roraima $\left(02^{\circ} 52^{\prime} 07^{\prime} ' \mathrm{~N}\right.$ e $60^{\circ} 43^{\prime} 03^{\prime}$ 'W). Parte desta área foi incorporada como um módulo de pesquisa do PPBio Amazônia.

A área de estudo apresenta uma superfície com cerca de 500 ha, apresentando as fitofisionomias como a savana arbórea, parque e graminosa, bem como outros sistemas como matas de galeria do rio Cauamé, afluentes do rio Branco, e matas de buritis. Estes ecossistemas de savana e florestais fazem parte da paisagem geral das savanas de Roraima
(Barbosa \& Miranda 2005).

De acordo com a classificação de Koeppen, o clima da região é o "Awi", tropical chuvoso com 5-7 meses de estação seca. A precipitação média anual é de $1614 \mathrm{~mm}$, sendo a maior concentração verificada entre os meses de maio e junho e a menor, entre dezembro e março (Barbosa 1997). O relevo é suavemente ondulado e os solos pertencem predominantemente ao grupo dos latossolos em mosaico com os podzólicos (Radambrasil 1975).

Coleta e análise de dados: O presente estudo envolveu a análise de materiais coletados e de exsicatas dos herbários MIRR (Herbário do Museu Integrado de Roraima) e UFRR (Herbário da Universidade Federal de Roraima). Para a coleta das plantas utilizou-se o método de caminhamento de Filgueiras et al. (1994), que consiste na coleta aleatória em trilhas pré-determinadas. Os registros fotográficos foram tomados para documentar e ilustrar o hábito, detalhes florais e de frutos.

As excursões foram realizadas entre março 2011 a março de 2012. As áreas selecionadas incluíram ambientes de savana e de mata ciliar. Todo material botânico coletado foi tombado no herbário do Museu Integrado de Roraima (MIRR).

Além dos materiais coletados, foram analisadas também exsicatas da família provenientes da área de estudo nas coleções dos herbários MIRR e UFRR. As amostras foram identificadas utilizando chaves de identificação de floras e revisões taxonômicas sobre a família (Mamede 1990; Anderson 2001) e também pela comparação com fotografias dos materiais tipos.

As informações sobre a distribuição geográfica e usos foram baseadas na literatura especializada, enquanto que as informações sobre habitat e demais comentários foram obtidos de dados constantes nas etiquetas e observações pessoais durante as coletas. A classificação adotada para denominar as fisionomias de savanas na área de estudo foi baseada em Barbosa \& Miranda (2005). A terminologia usada na descrição dos táxons foi baseada em Radford et al. (1974), Harris \& Harris (2001), Gonçalves \& Lorenzi (2007), bem como na bibliografia especializada na família como Mamede (1990) e Anderson (2001). 


\section{RESULTADOS E DISCUSSÃO}

$\mathrm{Na}$ área de estudo foram identificadas seis espécies de Malpighiaceae, pertencentes aos gêneros Byrsonima, Camarea e Tetrapterys. Byrsonima apresentou quatro espécies, todas previamente citadas por Miranda \& Absy (1997) para as savanas de Roraima, enquanto que Camarea affinis A. St.Hil. também havia sido registrada por Rodrigues (1971). Por outro lado, Tetrapterys styloptera representa um novo registro para a flora de Roraima.

\section{Descrição da família Malpighiaceae na área de estudo}

Arvoretas, subarbustos, arbustos eretos ou apoiantes. Folhas opostas, simples, com margens inteiras; estípulas frequentemente presentes, intrapeciolares. Inflorescências terminais ou axilares, pistilo-estaminadas, actinomorfas; cálice pentâmero, dialissépalo, geralmente com um par de glândulas secretoras de óleo dispostos na base de cada sépala; corola pentâmera, amarelas ou branco-rosadas, pétalas unguiculadas, com margens franjadas, pétala abaxial diferenciada em labelo; androceu com 4,8 ou 10 estames férteis, com 2 estaminódios em Camarea; gineceu tricarpelar, com três estiletes livres ente si, ovário súpero, com placentação axial. Frutos esquizocarpos, constituídos de três samarídeos, sâmaras ou drupáceos, indumento geralmente formado por tricomas simples intercalados com tricomas em forma de $\mathrm{T}$ (tricomas malpighiáceos).

1. Byrsonima coccolobifolia Kunth, Nov. Gen. Sp. (Quarto ed.) 5: 148. 1821-[1822]. Fig. 1 A Arvoretas ou arbustos, 2-3m alt. Ramos esparsamente pubérulos, alvos. Entrenós 2-3 $\mathrm{cm}$ compr. Estípulas 2-3 mm compr. Pecíolos ausentes. Folhas ovaladas, ápice obtuso a arredondado, base arredondada ou cordada, 7,1 $-10,6 \times 4,3-8 \mathrm{~cm}$, glabras ou glabrescentes em ambas as superfícies. Inflorescências terminais, 5,2-13,2 cm compr.; pedúnculos 1,7-3,2 cm compr. Brácteas 1,5-4 mm compr.; bractéolas 1,5-3 mm compr. Flores branco-rosadas; pedicelos 4-11 mm compr.; sépalas 3-4,5mm compr.; pétala posterior 7-8 x 4-4 mm, pétalas laterais 5-7 x 3-5 mm; gineceu glabrescente; androceu 10 estames férteis. Frutos drupáceos, imaturos verdes, maduros não vistos.

Ambientes preferenciais: $\mathrm{Na}$ área de estudo, a espécie pode ser encontrada em todos os tipos de fisionomias de savanas, principalmente em savana parque.

Observações: Segundo Mamede (2013a) esta espécie ocorre em Roraima, Amazonas, Tocantins, Bahia, Sergipe, Goiás, Mato Grosso, Distrito Federal, Mato Grosso do Sul, Minas Gerais, São Paulo e Paraná. Byrsonima coccolobifolia é facilmente reconhecida por ser a única arvoreta com folhas sésseis e flores branco-rosadas. $\mathrm{Na}$ área de estudo foi observada a presença de muitas formigas

\section{Chave de identificação para as espécies de Malpighiaceae na área de estudo}

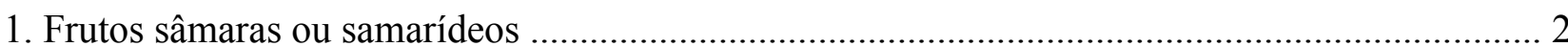

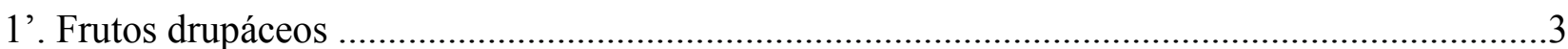

2. Subarbustos eretos; folhas sésseis; flores cleistógamas e casmógamas; frutos

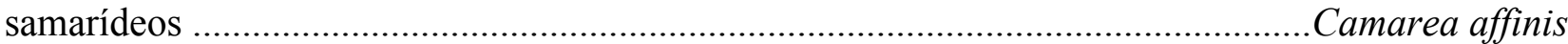
2'. Arbustos apoiantes ou lianas; folhas pecioladas; flores somente casmógamas; frutos sâmaras Tetrapterys styloptera

3'. Folhas sésseis Byrsonima coccolobifolia

3. Folhas pecioladas .. .4

4. Sépalas 5-8 $\mathrm{mm}$ compr.

4'. Sépalas 2-4 mm compr.

Byrsonima schomburgkiana

5. Presença de caules subterrâneos; folhas velutinas em ambas as superfícies, base atenuada; Entrenós geralmente nulos Byrsonima verbascifolia 5'. Ausência de caules subterrâneos; folhas glabras em ambas as superfícies ou furfurácea na superfície abaxial, base cuneada; Entrenós 1,2-3 cm compr. 
forrageando as inflorescências. Esta espécie é conhecida popularmente como "mirixi", "mirixi -caju" e "murici" e segundo Melo \& Barbosa (2007) a sua madeira é muito utilizada como lenha.

Material examinado: BRASIL. RORAIMA. Boa Vista, Campus Cauamé da UFRR, 24 jan. 2008, fl, A.S. Flores et al. 1723 (MIRR); id., 01 abr. 2011, bot, J. Menezes et. al 25 (MIRR); id., 01 abr. 2011, fl, J. Menezes et al. 32 (MIRR); id., 22 mar. 2012, fl, J. Menezes et al. 38 (MIRR); id., 22 mar. 2012, fl, J. Menezes et al. 39 (MIRR).

2. Byrsonima crassifolia (L.) Kunth, Nov.Gen. Sp. (Quarto ed.) 5: 149. 1821 [1822]

Malpighia crassifolia L., Sp. P1. 426. 1753.

Fig. 1 B, C

Arvoretas ou arbustos, $4 \mathrm{~m}$ alt. Ramos pubérulos, alvos a ferrugíneos. Entrenós 1,2-3 cm compr. Estípulas 2-5 mm compr. Pecíolos 6 $-12 \mathrm{~mm}$ compr. Folhas ovaladas, obovais ou elípticas, ápice agudo, acuminado ou arredondado, base cuneada, 6,2-18 x 3,5-6 cm, superfície adaxial glabra e superfície abaxial glabra ou furfurácea com tricomas ferrugíneos. Inflorescências terminais, 4,6-8,2 cm compr.; pedúnculos 1,5- 4,7 cm compr. Brácteas 1-3 mm compr.; bractéolas 1-2 mm compr. Flores amarelas; pedicelos 4-11 mm compr.; sépalas 3 $-4 \mathrm{~mm}$ compr.; pétala posterior $3-8 \times 3-13 \mathrm{~mm}$, pétalas laterais $4-8 \quad \mathrm{x} \quad 4-9 \mathrm{~mm}$; gineceu glabrescente; androceu 10 estames férteis. Frutos drupáceos, amarelos, 9-11 mm larg.

Ambientes preferenciais: $\mathrm{Na}$ área de estudo, esta espécie foi encontrada em borda de mata ciliar, savana graminosa, savana parque e área de transição mata ciliar e savana.

Observações: Esta espécie ocorre do México até o Brasil. Segundo Mamede (2013a), no Brasil ocorre nos estados de Roraima, Amapá, Pará, Tocantins, Maranhão, Piauí, Pernambuco, Bahia, Mato Grosso, Goiás, Distrito Federal, Mato Grosso do Sul, Minas Gerais, São Paulo.

Esta espécie é característica das savanas de Roraima sendo abundante em todos os tipos de fisionomia. Byrsonima crassifolia é de grande importância econômica, pois seus frutos são utilizados na produção de licores, sorvetes e polpas pela população local, sendo conhecida popularmente por "mirixi", "murici" e "muruxi" (Melo \& Barbosa 2007).

Material examinado: BRASIL. RORAIMA. Boa Vista, Campus do Cauamé da UFRR, 25 jan. 2011, bot, J. Menezes et al. 16 (MIRR); id.,
17 set. 2007, fl, R. S. Rodrigues 1636 (MIRR); id., 01 abr. 2011, fl, J. Menezes et al. 26 (MIRR); id., 24 jan. 2008 fl, A.S. Flores et al. 1709 (MIRR); id., 01 abr. 2011, fl, J. Menezes et al. 29 (MIRR); id., 05 mai 2010, fl, J. Menezes 07A (MIRR); id., 24 abr. 2007, fl, $A$. S. Flores et al. 1511(MIRR); id. 01 abr. 2011, fl, J. Menezes et al. 28 (MIRR); id., 01 abr. 2011, fl, J. Menezes et al. 34 (MIRR); id., 01 abr. 2011, fl, J. Menezes et al. 22 (MIRR); id., 01 abr. 2011, fl, J.Menezes et al. 27 (MIRR); id., 01 abr. 2011, fl, J. Menezes et al. 31 (MIRR); id., 01 abr. 2011, bot, J. Menezes et al. 20 (MIRR); id., 20 jul. 2007, fl, A. S. Flores 1724 (MIRR); 22 mar. 2012, fl, fr., J. Menezes et al. 40 (MIRR).

3. Byrsonima schomburkiana Benth., London J. Bot. 7: 123. 1848

Fig. $1 \mathrm{D}, \mathrm{E}$

Árvores, 5m alt. Ramos esparsamente tomentosos, alvos. Entrenós 0,3-0.8 cm compr. Estípulas 3-4 mm compr. Pecíolos 5-8 mm compr. Folhas elípticas ou obovadas, ápice agudo, mucronado a arredondado, base cuneada, 12-14,5 x 5-6 cm, glabras ou glabrescentes em ambas as superfícies. Inflorescências terminais, $13,5-16 \mathrm{~cm}$ compr.; pedúnculos 3-3,5 $\mathrm{cm}$ compr. Brácteas 3-5 mm compr.; bractéolas 2-3 mm compr. Flores não vistas; pedicelos 8-11 mm compr.; sépalas (5)6 $-8 \mathrm{~mm}$ compr.; pétalas não vistas; gineceu e androceu não vistos. Frutos drupáceos, imaturos verdes, maduros não vistos.

Ambientes preferenciais: $\mathrm{Na}$ área de estudo, esta espécie foi coletada somente em áreas de mata ciliar.

Observação: Esta espécie é encontrada nas Américas Central e do Sul. Para o Brasil, Anderson (2001) cita somente para o estado de Roraima, enquanto que Mamede (2013a) cita também para o Acre.

$\mathrm{Na}$ área de estudo, esta espécie distingue-se das demais espécies de Byrsonima por apresentar as sépalas alongadas de $5-8 \mathrm{~mm}$ de comprimento enquanto que as demais apresentaram sépalas de 2-4,5 $\mathrm{mm}$. Segundo Anderson (2001), B. schomburgkiana possui flores branco-rosadas e a principal característica em fruto desta espécie é apresentar as sépalas persistentes, alongadas, pelo menos duas vezes mais longas do que largas.

Material examinado: BRASIL. RORAIMA. Boa Vista, Campus Cauamé da UFRR, 20 out. 
2006, fr., A. S. Flores et al. 1377 (MIRR).

Material adicional: BRASIL. RORAIMA. Boa Vista, margem direita do igarapé do Cajual, afluente do Uraricoera, 12 nov. 1991, fr., E. Sette-Silva et al. 2126 (MIRR). Alto Alegre, ESEC Maracá, 3 22’N 61 25’W, 05 mar. 1987, fr., J. A. Ratter et al. 5560 (MIRR); Id., 14 out. 1987, fl., W. Milliken 728 (MIRR).

4. Byrsonima verbascifolia (L.) DC, Prodr. 1: 579. 1824.

Malpighia verbascifolia L., Sp. PI. 426. 1753.

Fig. $1 \mathrm{~F}$

Arbustos a subarbustos anões, 0,5-1 $\mathrm{m}$ alt. Ramos velutinos, alvos. Entrenós nulos. Estípulas 3-7 mm compr. Pecíolos 10-20 mm compr. Folhas obovais a arredondadas com ápice agudo a arredondado, base atenuada, 11,2 $-19 \times 4,6-10 \mathrm{~cm}$, velutinas em ambas as superfícies. Inflorescências terminais, 9,2-31 cm compr.; pedúnculos 7,3-12 cm compr. Brácteas 5-6,5 mm compr.; bractéolas 4-5 mm compr. Flores amarelas; pedicelos 1-8 mm compr.; sépalas 2-3 $\mathrm{mm}$ compr.; pétala posterior 3-6 x 3-9 mm; pétalas laterais 4-7 x 5$7 \mathrm{~mm}$; gineceu velutino; androceu com 10 estames férteis. Frutos drupáceos, maduros não vistos.

Ambientes preferenciais: $\mathrm{Na}$ área de estudo, esta espécie foi coletada somente em áreas de savana graminosa.

Observação: Esta espécie é encontrada nas Américas Central e do Sul. No Brasil, segundo Mamede (2013a), ocorre em Roraima, Bahia, Alagoas, Mato Grosso, Goiás, Distrito Federal, Mato Grosso do Sul, Minas Gerais, São Paulo e Paraná.

Esta espécie caracteristicamente não apresenta entrenós ou são quase inconspícuos, o que auxilia a distinguir-se de $B$. crassifolia que apresenta entrenós desenvolvidos. Entretanto, na área de estudo foram observados indivíduos (Menezes et al. 30 e 18) com entrenós visíveis de 16-30 mm compr., confirmando o observado por Anderson (2001), que poderia estar indicando uma possível hibridização desta espécie com $B$. crassifolia. Segundo Melo \& Barbosa (2007) conhecida pela população como "orelha- de- burro", "orelha- de- veado" e "mirixi-anão", usada pelos índios de Roraima em chá no tratamento de problemas intestinais.

Material examinado: BRASIL. RORAIMA. Boa Vista, Campus Cauamé da UFRR, 10 out. 2010, bot, A. S. Flores 2462 (MIRR); id., 01 abr. 2011, est, J. Menezes et al. 19 (MIRR); id., 01 abr. 2011, fl, J. Menezes et al. 21 (MIRR); id., 01 abr. 2011, fl, J. Menezes et al. 23 (MIRR); id., 01 abr. 2011, fl, J. Menezes et al. 24 (MIRR); 01 abr. 2011, fr, J. Menezes et al. 33 (MIRR).

5. Camarea affinis A.St.-Hil., Hist. Pl. Remarq. Brésil: 157.1824.

Fig. 2 A, B, C, D

Subarbustos eretos, $30-40 \mathrm{~cm}$ alt.; xilopódios presentes. Ramos hirsutos. Estípulas $1 \mathrm{~mm}$ compr. Pecíolos ausentes. Folhas elípticas a lanceoladas, ápice agudo, base arredondada, $1,9-2,9 \times 4-4 \mathrm{~cm}$, hirsuta em ambas as superfícies. Flores casmógamas dispostas em inflorescências cimosas uni a multifloras, terminais, 2,9-4 cm compr. Pedúnculos 10-11 $\mathrm{mm}$ compr. Brácteas foliáceas, $1 \mathrm{~cm}$ compr.; bractéolas $1 \mathrm{~mm}$ compr. Flores casmógamas, amarelas, sépalas 2-3 mm compr., unidas na base sendo uma aglandular; pétala posterior $7 \mathrm{x}$ 3-4 $\mathrm{mm}$, pétalas laterais $4-7 \mathrm{~mm}$ compr.; gineceu esparsamente seríceo; androceu com 4 estames férteis e 2 estaminódios. Flores cleistógamas, inconspícuas, em inflorescências unifloras, axilares. Frutos samarídeos em flores cleistógamas e casmógamas 5-6 x 2,5-4,5 mm, sem ala dorsal, núcleo seminífero glabro, aculeado, aréola ventral côncava.

Ambientes preferenciais: Na área de estudo, esta espécie foi coletada em áreas de savana graminosa e savana aberta.

Observações: Encontrada no Brasil, Guiana e Paraguai. No Brasil, segundo Mamede (2013b), ocorre nos estados do Maranhão, Bahia, Mato Grosso, Goiás, Distrito Federal, Mato Grosso do Sul, Minas Gerais e São Paulo.

Esta espécie é de fácil identificação na área de estudo por ser a única que apresenta flores cleistógamas e casmógamas e xilopódio desenvolvido. No Brasil, a espécie que mais se aproxima dela é $C$. hirsuta A. St.-Hill. pela presença de flores cleistógamas localizadas nas axilas das folhas basais, diferenciando-se desta por apresentar samarídeos sem ala dorsal (Mamede 1990). C. hirsuta não é citada para Roraima, ocorre nos estados de Goiás, São Paulo e Minas Gerais (Mamede 2013b).

Estudos fitoquímicos em Camarea mostram um possível potencial farmacológico, devido à presença de algumas substâncias já isoladas tais como quinonas, curmarinas e triterpenos, gerando atividade analgésica (Motta 2007).

Material examinado: BRASIL. RORAIMA. 

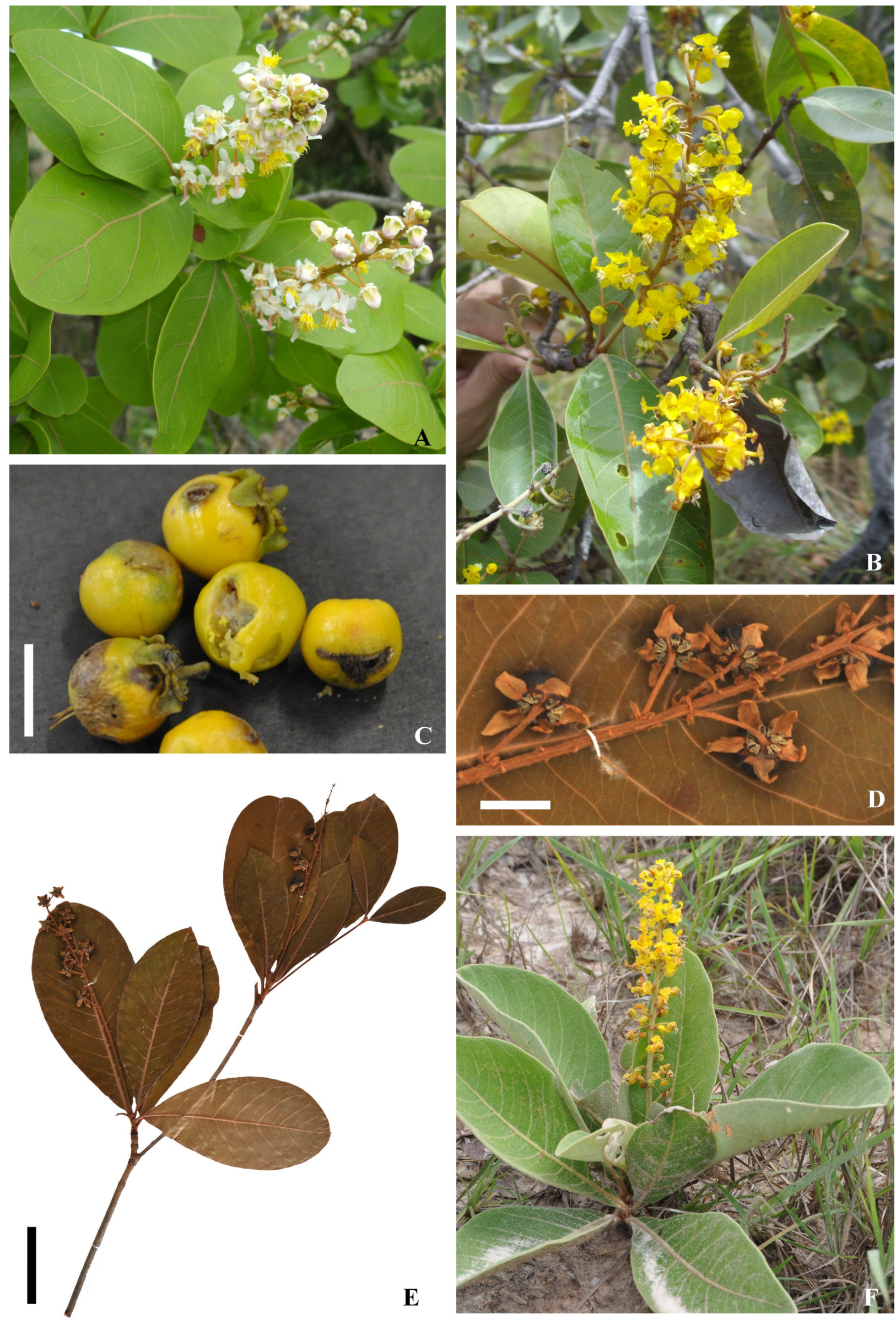

Figura 1. Espécies de Malpighiaceae em uma área de savana em Boa Vista, Roraima, Brasil. A. Ramo com flores de Byrsonima coccolobifolia Kunth. B. Ramo com flores de Byrsonima crassifolia (L.) Kunth. C. Frutos drupáceos de Byrsonima crassifolia (escala $1 \mathrm{~cm}$ ). D. Detalhe de ramo com frutos imaturos de Byrsonima schomburgkiana Benth. (escala $1 \mathrm{~cm}$ ). E. Ramo com frutos imaturos de Byrsonima schomburgkiana (escala $5 \mathrm{~cm}$ ). F. Hábito de Byrsonima verbascifolia (L.) DC. 

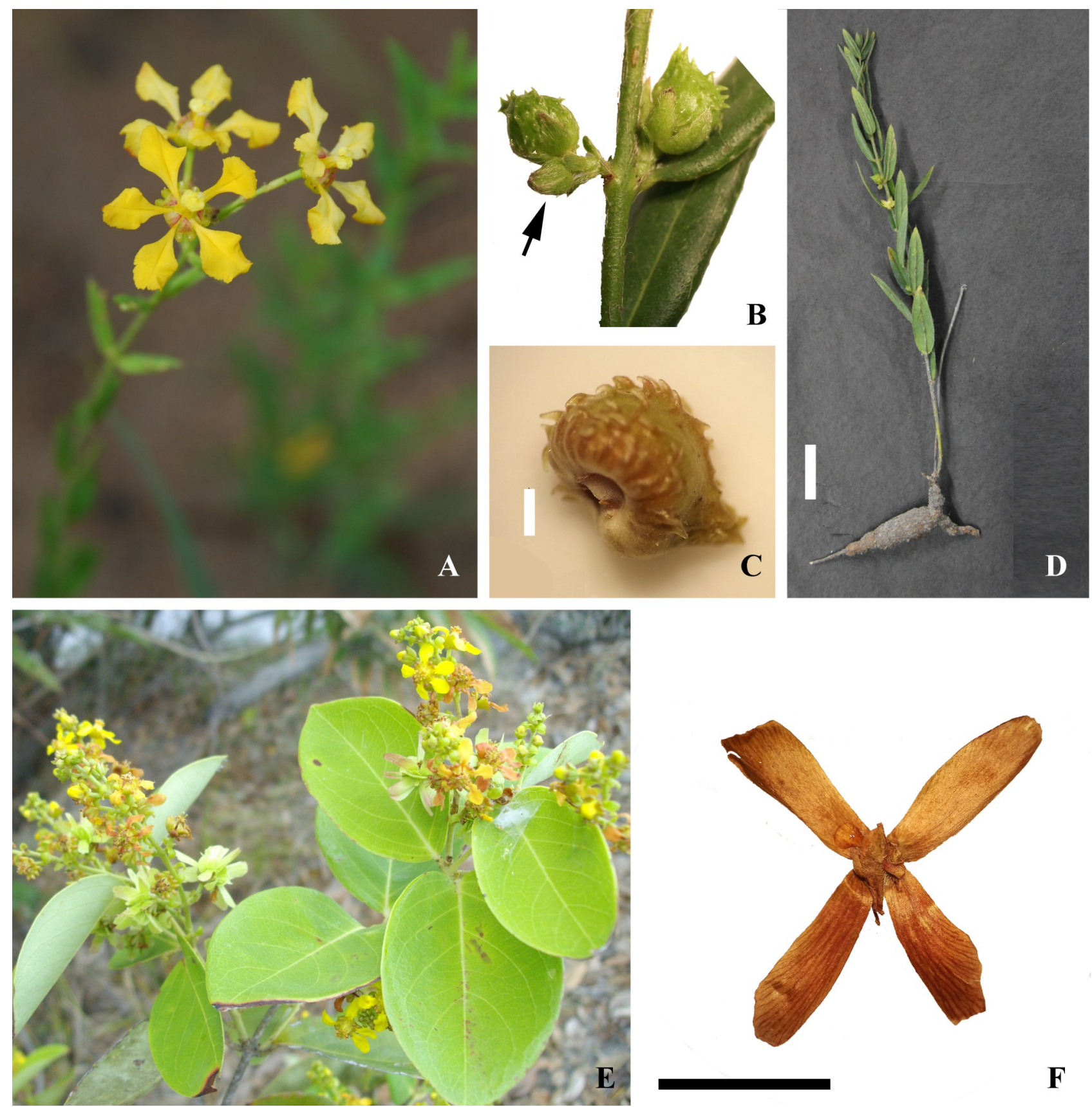

Figura 2. Espécies de Malpighiaceae em uma área de savana em Boa Vista, Roraima, Brasil. A. Ramo com flores de Camarea affinis A. St.-Hil. B. Detalhe de flor cleistógama (seta) e frutos imaturos de Camarea affinis. C. Samarídeo de flores cleistógamas de Camarea affinis (escala $1 \mathrm{~mm}$ ). D. Aspecto geral de Camarea affinis com xilopódio. E. Ramo com flores e frutos de Tetrapterys styloptera A. Juss. F. Detalhe de fruto de Tetrapterys styloptera (escala $1 \mathrm{~cm}$ ).

Boa Vista, Campus do Cauamé da UFRR 05 mai. 2010, fl, J. Menezes 05A (MIRR); id., 23 jun. 2007, fl, A. S. Flores 2293 (MIRR); id., 05 mar. 2012, fr, J. Menezes 41 \& A. S. Flores (MIRR).

6. Tetrapterys styloptera A. Juss., Ann. Sci. Nat., Bot. sér. 2, 13: 262. 1840.

Fig. 2 E, F

Lianas ou arbustos, apoiantes. Ramos seríceos ou glabros. Estípulas 1-3 mm compr. Pecíolos 3-4 mm compr. Folhas arredondadas, ápice agudo ou arredondado, mucronado, base arredondada 4,4-6,9 x 2,2-4,6 cm, superficie adaxial glabra, superficie abaxial esparsamente serícea. Inflorescências terminais, 2,3-4,9 cm compr.; pedúnculos 4-17 mm compr. Brácteas 1-3 compr.; bractéolas 1-4 mm compr. Flores amarelas; pedicelos 2-5 mm compr.; sépalas 2$\mathrm{mm}$ compr., pétala posterior 4-5 x 2-3 mm, pétalas laterais 4-8 x 3-4 mm; gineceu seríceo; androceu com 10 estames férteis. Frutos sâmaras, alas superiores 4-14 mm compr., alas inferiores 4-10 mm compr., núcleo seminífero 


\section{3-6 mm compr.}

Ambientes preferenciais: $\mathrm{Na}$ área de estudo foi coletada em mata ciliar às margens do rio Cauamé sobre solos pedregosos e em beira de mata.

Observações: Esta espécie ocorre na Nicarágua, Panamá, Colombia, Guiana, Suriname, Guiana Francesa, Peru amazônico, Brasil e Bolívia. No Brasil ocorre somente na região Norte, nos estados do Amapá, Pará e Amazonas (Mamede 2013c).

Tetrapterys styloptera é uma nova ocorrência para Roraima. A única espécie do gênero mencionada por Mamede (2013c) para Roraima foi $T$. discolor (G. Mey.)DC que possui sua ocorrência confirmada para $\mathrm{o}$ Estado, mas é ausente na área de estudo. Tetrapterys styloptera possui fruto sâmara com ala dorsal superior igual a inferior enquanto que $T$. discolor possui ala superior maior que a inferior.

Material examinado: BRASIL. RORAIMA. Boa Vista, Campus do Cauamé da UFRR, 24 jan. 2008, fr, A. S. Flores et al. 1730 (MIRR); id., 24 jan. 2008 fl, fr, A. S. Flores et al. 1726 (MIRR) ; id., 24 abr. 2007, fl, A. S. Flores et al. 1512 (MIRR); id., 25 jan. 2012, bot, J. Menezes et al. 11 (MIRR); id., 24 jan. 2008, fl, fr, $A$. S. Flores et al. 1717 (MIRR); id., 20 out. 2006 , fl, fr, A. S. Flores et al. 1383 (MIRR); id., 17 jun. 2002 fl, fr, L. A. Pessoni \& I. G. Silva 485 (UFRR); id., 30 mai. 2002, fl, D. L. Batista et al. 3 (UFRR); id., 15 ago. 2003, fr, N. $A$. Gomes 76 (UFRR).

\section{AGRADECIMENTOS}

As autoras agradecem o apoio prestado pelo Dr. Rodrigo Schütz Rodrigues na busca de bibliografias e auxílio na montagem das pranchas. As biólogas Elayne Medeiros e Mônica Celi pelo auxílio nas coletas; Janderson Baima pelo auxílio na busca nos bancos de dados no herbário MIRR; Silvana Stimer e Christiane Costa pelas sugestões. Aos assessores anônimos pela revisão crítica do manuscrito.

\section{REFERÊNCIAS BIBLIOGRÁFICAS}

Anderson, W. R. 2001. Malpighiaceae In: Steyermark J. A, Berry, P. E, Yatskievych, K \& Holst B. K (Eds) Flora of the Venezuela Guyana, St. Louis: Missouri Botanical Garden Press. v. 6, p. 316-347.

Barbosa, R. I. 1997. Distribuição das chuvas em Roraima. In: Barbosa, R. I.; Ferreira, E. J. G. \&
Castellón; E. G (Eds.). Homem, Ambiente e Ecologia no Estado de Roraima. Manaus: INPA. p. 325-335.

Barbosa, R. I. \& Miranda, I. S. 2005. Fitofisionomia e diversidade vegetal nas Savanas de Roraima. In: Barbosa, R. I.; Xaude, H. A. M. \& Costa E Souza, J. M. (Eds). Savanas de Roraima: etnoecologia, biodiversidade e potencialidades agrossilvipastoris. Boa Vista: FEMACT. p. 61-78.

Costa, C.S., Flores, A.S. \& Rodrigues, R.S. 2012. A família Polygalaceae em uma área de savana em Roraima, Brasil. Revista Brasileira de Biociencias 10 (4): 468-480.

Filgueiras, T. S.; Nogueira, P. E. ; Brochado, A. L. \& Gaala Li, G. F. 1994. Caminhamento: um método expedido para levantamentos florísticos qualitativos. Cadernos de Geociências 12: 39-43.

Flores, A.S. \& Rodrigues, R.S. 2010. Diversidade de Leguminosae em uma área de savana de Roraima. Acta Botânica Brasílica 24 (1): 175-183.

Judd, W. S.; Campbell, C. S.; Kellogg, E.A.; Stevens, P.F. \& Donoghue, M. J. 2009. Sistemática Vegetal: um enfoque filogenético. Porto Alegre: Artmed.

Gonçalves, E. G. \& Lorenzi, H. 2007. Morfologia Vegetal: Organografia e Dicionário Ilustrado de Morfologia das Plantas Vasculares. Nova Odessa: Instituto Plantarum de Estudos da Flora. 416 p.

Harris, J. G. \& Harris M. W. 2001. Plant Identificacion Terminology: An Illustrated Glossary. 2nd ed. Spring Lake: Spring Lake Publishing. 206 p.

Mamede, M. C. H. 1990. Revisão do gênero Camarea Saint-Hilaire (Malpighiaceae). Hoehnea 17(1): 1-34.

Mamede, M.C.H.; Amorim, A.M.A. \& Sebastiani, R. 2013. Malpighiaceae. In: Lista de Espécies da Flora do Brasil. Jardim Botânico do Rio de Janeiro. (http:// floradobrasil.jbrj.gov.br/jabot/floradobrasil/FB155) Acesso em: 02 de Out. de 2013.

Mamede, M.C.H. 2013a. Byrsonima In: Lista de Espécies da Flora do Brasil. Jardim Botânico do Rio de Janeiro. (http://floradobrasil.jbrj.gov.br/jabot/ floradobrasil/FB8831) Acesso em: 02 de Out. de 2013.

Mamede, M.C.H. 2013b. Camarea. In: Lista de Espécies da Flora do Brasil. Jardim Botânico do Rio de Janeiro. Disponível em: (http:// floradobrasil.jbrj.gov.br/jabot/floradobrasil/ FB19435). Acesso em 03 Mar 2012.

Mamede, M.C.H. 2013c. Tetrapterys. In: Lista de Espécies da Flora do Brasil. Jardim Botânico do Rio de Janeiro. Disponivel em: (http:// floradobrasil.jbrj.gov.br/jabot/floradobrasil/FB8967). Acesso em: 03 Out. de 2013.

Melo, M. C. \& Barbosa, R. I. 2007. Árvores e arbustos das savanas de Roraima: Guia de campo ilustrado. Boa Vista, PMBV/ CONSEMMA.

Miranda, I. S. \& Absy, M. L. 1997. A flora fanerogâmica 
das savanas de Roraima. In: Barbosa, R. I. \& Ferreira, E. J. G.; Castellón; E.G. (Eds.). Homem, Ambiente e ecologia no estado de Roraima. Manaus; INPA. p. 445-462.

Motta, L. B. 2007. Aspectos químicos e moleculares ligados a filogenia de Camarea [Tese de doutorado], Universidade de São Paulo, SP.

Radambrasil. 1975. Folha NA.20. Boa Vista e partes de folhas NA.21. Tumucumarque, NB. 20 E NB.21 (Geologia, geomorfologia, pedologia, vegetação e uso potencial da terra). Rio de Janeiro: Ministério da Minas Energia. v. 8, 427 p.

Radford, A. E., Dickison, W. C., Massey, J. R. \& Bell, C. R. 1974. Vascular Plant Systematics. New York: Harper \& Row. 891 p.

Ribeiro, J.E.L.S.; Hopkins, M.J.G. \& Vicentini, A. et al. 1999. Floresta da reserva Ducke: guia de identificação das plantas vasculares de uma floresta de terra-firme na Amazônia Central. INPA, Manaus.

Rodrigues, W. A. 1971. Plantas dos campos do Rio Branco (Território de Roraima). In: M. G. Ferri. (Coord.) III Simpósio sobre cerrado. São Paulo.

Souza, V. C. \& Lorenzi, H. 2008. Botânica Sistemática: guia ilustrado para identifição de famílias de fanerógamas nativas e exótica no Brasil, baseado no APG III. $2^{\mathrm{a}}$ Ed. Nova Odessa, SP: Instituto Plantarum. 704 p.

Lista de exsicatas:

Batista, D.L.: 3 (6-UFRR)

Flores, A.S.: 1377 (3-MIRR); 1383 (6-MIRR); 1511 (2MIRR); 1512 (6-MIRR); 1709 (2-MIRR); 1717 (6MIRR); 1723 (1-MIRR); 1724 (2-MIRR); 1726 (6MIRR) ; 1730 (5-MIRR); 2293 (5-MIRR); 2462 (4MIRR)

Gomes, N.A.: 76 (6-UFRR)

Menezes, J.: 05A (5-MIRR); $07 A$ (2-MIRR); 11 (6MIRR); 16 (2-MIRR); 19 (4-MIRR); 20 (2-MIRR); 21 (4-MIRR); 22 (2-MIRR); 23 (4-MIRR); 24 (3MIRR); 25 (1-MIRR); 26 (2-MIRR); 27 (2-MIRR); 28 (2-MIRR); 29 (2-MIRR); 31 (2-MIRR); 32 (1MIRR); 33 (4-MIRR); 34 (2-MIRR);38 (1-MIRR); 39 (1-MIRR); 40 (2-MIRR); 41 (5-MIRR)

Milliken $W .: 728$ (3-MIRR)

Pessoni, L.A.: 485 (6-UFRR)

RatterJ.A.: 5560 (3-MIRR)

Rodrigues, R.S.: 1636 (2-MIRR)

Sette-Silva E.: 2126 (3-MIRR). 